\title{
Dampak Pembangunan Jembatan Bahteramas Terhadap Kondisi Sosial Ekonomi Masyarakat Pesisir di Kelurahan Poasia Kecamatan Abeli Kota Kendari Sulawesi Tenggara
}

\author{
Asrianti Dja'wa1*, Rudi Abdullah², Sandi Saputra ${ }^{1}$, Burhan Asril Jabani ${ }^{1}$, Muh. Idul \\ Firmansyah $^{1}$ \\ ${ }^{1}$ Fakultas Ekonomi dan Bisnis, Universitas Halu Oleo, Indonesia \\ ${ }^{2}$ Fakultas Ekonomi, Universitas Muhammadiyah Buton, Indonesia \\ "Korespondensi: asrianti.djawa@uho.ac.id
}

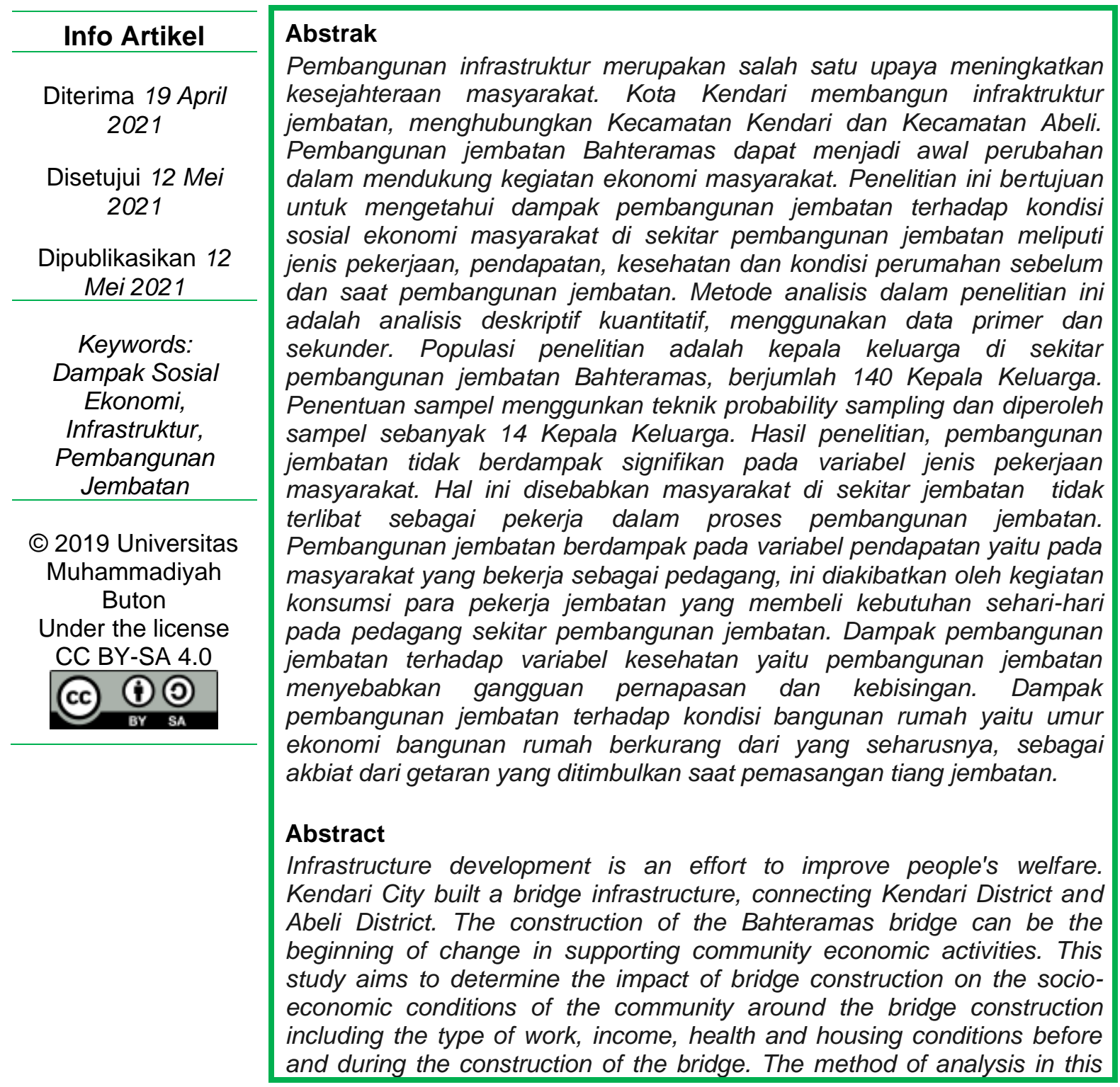




\begin{abstract}
research is quantitative descriptive analysis, using primary and secondary data. The study population was the heads of families around the Bahteramas bridge construction, totaling 140 heads of households. Determination of the sample using probability sampling techniques and obtained a sample of 14 households. The results showed that the construction of bridges did not have a significant impact on the variable type of community work. This is because the people around the bridge are not involved as workers in the bridge construction process. The construction of the bridge has an impact on the income variable, namely the people who work as traders, this is caused by the consumption activities of bridge workers who buy daily necessities from traders around the bridge construction. The impact of bridge construction on health variables, namely the construction of bridges causing respiratory problems and noise. The impact of bridge construction on the condition of the house building is that the economic age of the house building is reduced than it should be, as a result of the vibrations generated when installing bridge poles.
\end{abstract}

\title{
1. Pendahuluan
}

Pada hakikatnya pembangunan merupakan upaya yang bertujuan untuk meningkatkan kesejahteraan masyarakat. Pelaksanaan pembangunan mencakup beberapa aspek diantaranya adalah aspek ekonomi, social, politik dan keamanan dengan tujuan untuk mencapai pemerataan pembangunan bagi seluruh lapisan masyarakat. Salah satu bentuk upaya tersebut ialah melalui pembanguan infrastruktur yang dilakukan oleh pemerintah.

Ketersedian infrastruktur dapat mendukung kegiatan ekonomi masyarakat, memacu distribusi aliran barang dan jasa sehingga mempermurah biaya produksi benda dan jasa. Seperti yang dikemukakan oleh Hirchman (1958) dalam Pamungkas Bagus T (2009) bahwa infrastruktur sebagai suatu yang sangat diperlukan, tanpa infrastruktur kegiatan produksi pada berbagai kegaiatan sektor ekonomi (industri) tidak dapat berjalan dengan baik.

The Routledge Dictionary of Ecomics (1995) memberikan penjalasan yang lebih luas bahwa infrastruktur adalah pelayan utama dari sebuah negeri yang dapat menyokong kegiatan ekonomi dan kegiatan masyarakat sehingga mampu berlangsung, hal ini melalui penyediaan transportasi dan sarana pendukung yang lain. Jadi dapat disimpulkan bahwa secara makro dengan adanya infraktruktur akan memacu kegiatan ekonomi, pada akhirnya akan meningkatkan pertumbuhan ekonomi dan meningkatkan kesejahteraan masyarakat. Namun setiap proses pembangunan infrastruktur akan memberi dampak langsung bagi kondisi sosial ekonomi masyarakat yang barada di sekitar pembangunan.

Kajian mengenai dampak pembangunan infrakstruktur, telah banyak dilakukan. Hasil temuan menunjukkan bahwa terdapat dampak positif dengan adanya pembangunan, namun tidak sedikit pula memiliki dampak negative. Hasil penelitian yang dilakukan oleh lek (2013) dampak pembangunan jalan di Papua Barat, menunjukkan bahwa pembangunan jalan memiliki dampak positif yang signifikan terhadap perubahan sosial ekonomi masyarakat. Demikian juga Sudarsana (2011) melakukan kajian ekonomi dengan adanya pembangunan jalan penghubung Bali Utara-Selatan, disimpulkan bahwa keuntungan proyek secara langsung berupa penghematan biaya operasi (PBOK) serta menghemat waktu, 
keuntungan tidak langsung yakni bertambahnya jumlah wisatawan yang meneruskan perjalan ke Bali Utara, meningkatnya sektor usaha serta menurunnya angkan kecelakaan. Penelitian serupa juga dilakukan oleh Prawiro (2014) yang melakukan penelitian dampak pembangunan jalan layang, hasil penelitiannya bahwa mayoritas respondem di sepanjang jalan mengalami gangguan berupa kebisingan, polusi udara, kemacetan lalu lintas.

Pemerintah Kota Kendari sejak Agustus 2015 membangun infrasktur jembatan yang menghubungkan antara wilayah yang ada di Kecamatan Kendari dan Kecamatan Abeli. Tujuan pembangunan jembatan ini ialah memperlancar arus lalu lintas, serta meningkatkan konektivitas antar wilayah sehingga di harapkan dapat membantu proses percepatan pembangunan wilayah di Kota Kendari. Penelitian yang dilakukan Ruslan (2018) tentang dampak pembangunan jembatan Bahteramas bagi masyarakat yang ada di sisi sebelah jembatan di kelurahan Kandai, Kecamatan Kendari bahwa pembangunan jembatan Bahteramas yang berada di Kelurahan Kandai memiliki dampak negatif bagi masyarakat yaitu hilangnya sumber pendapatan masyarakat yang ada di kawasan proyek pembangunan jembatan, sebab daerah sebelum adanya pembangunan jembatan merupakan pusat pertokoan (kota lama) di Kota Kendari. Selain itu dengan adanya pebangunan jembatan Bahteramas memimbulkan polusi udara akibat dari proses pembangunan jembatan, terjadi konflik pembebasan lahan sebagai akibat dari penolakan masyarakat terhadap penggusuran di Kota Lama yang menjadi kawasan pembangunan jembatan.

Hasil penelitian Ruslan (2018) juga menemukan bahwa selain dampak negative, terdapat dampak positif adanya pembangunan jembatan Bahteramas terhadap masyarakat di Kelurahan Kandai, yaitu terciptanya lapangan kerja baru untuk masyarakat yang tinggal di sekitar lokasi pembangunan jembatan. Namun, penelitian yang dikalukan hanya melihat kondisi dampak pembangunan jembatan Bahteramas dari sisi masyarakat yang ada di Kelurahan Kandai Kecamatan Kendari, yang memiliki mata pencaharian mayoritas pada sektor perdagangan dan jasa. Sedangkan di sisi jembatan yang ada di Kelurahan Poasia Kecamatan Abeli, mayoritas masyarakatnya bekerja sebagai nelayan. Sehingga tidak dapat diambil kesimpulan yang sama, bahwa kedua masyarakat memperoleh dampak yang sama dengan adanya pembangunan jembatan Bahteramas. Perbedaan karakteristik mata pencahatian tersebut yang kemudian melatar belakangi pentingnya peneltian ini dilakukan yakni melihat bagaimana dampak sosial ekonomi masyarakat yang berada di Kelurahan Poasia, Kecamatan Abeli dilihat dari variabel jenis pekerjaan, tingkat pendapatan, kesehatan dan kondisi perumahan sebelum dan saat pembangunan jembatan Bahteramas.

\section{Metode Penelitian}

Lokasi penelitian dilaksanakan di Kelurahan Poasia yaitu di sekitar proyek pembangunan jembatan dengan objek kajian kondisi sosial ekonomi masyarakat pesisir yang terkena dampak pembangunan jembatan bahteramas yang meliputi jenis pekerjaan, tingkat pendapatan, dan kondisi perumahan sebelum dan saat pembangunan jembatan bahteramas.

Adapun populasi dalam penelitian ini yakni kepala keluarga yang bermukin di pesisir teluk Kendari yang berada di sekitar pembangunan jembatan Bahteramas Kelurahan Poasia, berjumlah 104 Kepala Keluarga. Jumlah sampel dalam 
penelitian ini sebanyak 14 Kepala Keluarga. Pemilihan sampel dilakukan berdasarkan pendapat Arikunto (2006) bahwa jika populasinya kurang dari 100, maka populasi lebih baik diambil seluruhnya, sehingga penelitiannya disebut penelitian populasi. Sedangkan jika populasinya besar dapat diambil antara 10 persen - 15 persen atau 20 persen - 30 persen atau lebih.

Jenis data dalam penelitian ini terdiri atas data kuantitatif dan kualitatif yaitu berupa data sekunder yang berasal dari BPS Kota Kendari, Kantor Lurah Poasi, serta data primer yang didapatkan langsung dari responden. Metode pengumpalan data melalui survey lapangan dan wawancara.

Adapun analisis data mengunakan analisis statistik deskriptif, yaitu mendeskripsikan kondisi sosial ekonomi masyarakat pesisir yang mencakup variabel jenis pekerjaan, tingkat pendapatan, kesehatan serta kondisi rumah. Pada umumya dalam analisis ini hanya menghasilkan distribusi frekuensi dan persentase pada tiap variabel.

\section{Hasil dan Pembahasan}

\subsection{Hasil}

\section{a. Jenis Pekerjaan}

Hasil penelitian menemukan bahwa jenis pekerjaan yang dilakukan oleh masyarakat pesisir di Kelurahan Poasia yang berada di sekitar pembangunan jembatan Bahteramas yaitu nelayan, pedagang, dan lainnya (buruh dan pekerja lepas). Sebelum adanya pembangunan jembatan sebanyak 50,00 persen sebagai nelayan, 28,57 persen sebagai pedagang dan 21,43 persen lainnya. Adanya pembangunan jembatan terjadi perubahan pada kompisisi jenis pekerjaan yaitu terjadi kenaikan pada jenis pekerjaan pedagang yaitu menjadi 35,71 persen atau naik sebesar 7,14 persen, hal ini disebabkan karena ada perubahan struktur pekerjaan dari kelompok lainnya (buruh dan pekerja lepas) menjadi pedagang. Sedangkan untuk masyarakat yang bekerja sebagai nelayan tetap tidak mengalami pergeseran jumlah, baik sebelum maupun dengan adanya pembangunan jembatan Bahteramas.

Berdasarkan hasil penelitian, pembangunan jembatan tidak berdampak signifikan pada jenis pekerjaan masyarakat sekitar pembangunan jembatan, keterlibatan masyarakat sebagai pekerja dalam pembangunan jembatan tidak ada. Masyarakat masih tetap bekerja pada tiga jenis pekerjaan yaitu nelayan, pedagang dan lainnya yang berubah hanya pada kompisisinya.

Tabel 1. Jenis Pekerjaan Masyarakat Pesisir di Kelurahaan Poasia Kecamatan Abeli Kota Kendari yang Berada di Kawasan Pembangunan Jembatan Bahteramas.

\begin{tabular}{lcccc}
\hline \multirow{2}{*}{ Jenis Pekerjaan } & \multicolumn{2}{c}{$\begin{array}{c}\text { Belum Ada Pembangunan } \\
\text { Jembatan }\end{array}$} & \multicolumn{2}{c}{ Ada Pembangunan Jembatan } \\
\cline { 2 - 5 } & Jumlah & Persentase (\%) & Jumlah & Persentase (\%) \\
\hline Nelayan & 7 & 50,00 & 7 & 50,00 \\
\hline $\begin{array}{l}\text { Pedagang } \\
\text { Lainnya (buruh dan } \\
\text { pekerja lepas) }\end{array}$ & 4 & 28,57 & 5 & 35,71 \\
\begin{tabular}{l} 
Jumlah \\
\hline
\end{tabular} & 14 & 21,43 & 2 & 14,29 \\
\hline
\end{tabular}

Sumber: Data Primer 2019 (diolah) 


\section{b. Tingkat Pendapatan}

Hasil penelitian menemukan bahwa tingkat pendapatan masyarakat pesisir di Kelurahan Poasia yang berada di sekitar pembangunan jembatan Bahteramas sebelum adanya pembangunan jembatan sebanyak 21,43 persen memiliki pendapatan di bawah Rp. 1.500.000; sebanyak 64,29 persen berada pada tingkat pendapatan Rp. 1.500 .000 - Rp. 3.500.000; sebanyak 7,14 persen berada pada tingkat pendapatan Rp. 3.500.001 - Rp. 5.500.000; dan sebanyak 7,14 persen berada pada tingkat pendapatan di atas Rp. 5.500,000.

Tabel 2. Pendapatan Masyarakat Pesisir di Kelurahaan Poasia Kecamatan Abeli Kota Kendari yang Berada di Kawasan Pembangunan Jembatan Bahteramas.

\begin{tabular}{lcccc}
\hline \multirow{2}{*}{ Tingkat Pendapatan (Rp) } & \multicolumn{2}{c}{$\begin{array}{c}\text { Belum Ada } \\
\text { Pembangunan Jembatan }\end{array}$} & \multicolumn{2}{c}{$\begin{array}{c}\text { Ada Pembangunan } \\
\text { Jembatan }\end{array}$} \\
\cline { 2 - 5 } & Jumlah & Persentase (\%) & Jumlah & Persentase (\%) \\
\hline$>1.500 .000$ & 3 & 21,43 & 3 & 21,43 \\
\hline $1.500 .000-3.500 .000$ & 9 & 64,29 & 7 & 50,00 \\
\hline $3.500 .001-5.500 .000$ & 1 & 7.14 & 3 & 21,43 \\
\hline$>5.500 .000$ & 1 & 7.14 & 1 & 7,14 \\
\hline Jumlah & 14 & 100,00 & 14 & 100,00 \\
\hline
\end{tabular}

Sumber: Data Primer 2019 (diolah)

Adanya pembangunan jembatan Bahteramas menyebabkan peningkatan pendapatan yaitu pada masyarakat yang berpedapatan di atas $\mathrm{Rp}$. 1.500 .000 meningkat. Namun pendapatan masyarakat yang berada di bawah Rp. 1.500.000 tidak mengalami perubahan baik sebelum adanya pembangunan jembatan maupun tidak. Berdasarkan data dapat diketahui bahwa perubahan kenaikan pendapatan ini bisa berasal dari perubahan struktur jenis pekerjaan yang mengalami perubahan pada jenis pekerjaan pedagang. Ini terjadi karena keberadan para pekerja jembatan dalam melakukan konsumsi banyak berbelanja di pedagang lokal.

c. Kondisi Kesehatan

Hasil penelitian terhadap variabel kondisi kesehatan masyarakat pesisir di Kelurahan Poaia Kecamatan Abeli Kota Kendari yang berada di kawasan pembangunan jembatan Bahteramas menunjukkan bahwa sebanyak 21,43 persen menyatakan kondisi kesehatan masyarakat baik sebelum ada pembangunan jembatan, sebanyak 78,57 persen menyatakan cukup baik.

Tabel 3 Kondisi Kesehatan Masyarakat Pesisir di Kelurahaan Poasia Kecamatan Abeli Kota Kendari yang Berada di Kawasan Pembangunan Jembatan Bahteramas.

\begin{tabular}{lcccc}
\hline \multirow{2}{*}{ Kondisi Kesehatan } & \multicolumn{2}{c}{$\begin{array}{c}\text { Belum Ada } \\
\text { Pembangunan } \\
\text { Jembatan }\end{array}$} & \multicolumn{2}{c}{$\begin{array}{c}\text { Ada Pembangunan } \\
\text { Jembatan }\end{array}$} \\
\cline { 2 - 5 } & $\begin{array}{c}\text { Jumla } \\
\mathrm{h}\end{array}$ & $\begin{array}{c}\text { Persentase } \\
(\%)\end{array}$ & $\begin{array}{c}\text { Jumla } \\
\mathrm{h}\end{array}$ & $\begin{array}{c}\text { Persentase } \\
(\%)\end{array}$ \\
\hline Baik & 3 & 21,43 & 1 & 7,14 \\
\hline Cukup Baik & 11 & 78,57 & 12 & 85,71 \\
\hline Kurang baik & 0 & 0 & 1 & 7,14 \\
\hline Jumlah & 14 & 100,00 & 14 & 100,00 \\
\hline
\end{tabular}




\section{Sumber: Data Primer 2019 (diolah)}

Pada saat pembangunan jembatan Bahteramas sebanyak 7,14 persen menyatakan bahwa kondisi kesehata baik. Jumlah ini mengalami penurunan dari sebelum ada pembangunan jembatan Bahteramas yaitu 21,43 persen menyatakan baik, namun setelah ada pembangunan turun sebesar 14,29 persen. Sebanyak 85,71 persen menyatakan dengan adanya pembangunan jembatan Bahteramas kondisi kesehatan cukup baik. Jumlah ini meningkat dari jumlah sebelum ada pembangunan jembatan. Artinya ada penambahan jumlah yang berasal dari kondisi baik menjadi cukup baik. Dan sebanyak 7,14 persen menyatakan kurang baik, sebelum adanya pembangunan tidak ada responden yang menjawab kurang baik. Masalah kesehatan yang dialami oleh masyarakat yang berada di kawasan pembangunan jembatan bahteramas adalah gangguan pernapasan dan kebisingan sebagai akibat dari debu dan peledakan bom dalam pembangunan jembatan.

\section{d. Kondisi Fisik Bangunan}

Hasil penelitian terhadap variabel kondisi bangunan rumah tinggal masyarakat pesisir di Kelurahaan Poasia Kecamatan Abeli Kota Kendari yang berada di kawasan pembangunan jembatan Bahteramas. Sebanyak 7,14 persen konstruksi bangunan rumah tinggal masyarakat terbuat dari kayu dengan lantai tanah, sebanyak 21,43 persen terbuat dari kayu dengan lantai semen, sebanyak 28,57 persen konstruksi bangunan semi permanen dan 42,86 persen kontruksi rumah permanen.

Tabel 4 Kondisi Bangungan Rumah Tinggal Masyarakat Pesisir di Kelurahaan Poasia Kecamatan Abeli Kota Kendari yang Berada di Kawasan Pembangunan Jembatan Bahteramas.

\begin{tabular}{lcc}
\hline Konstruksi Bangunan Rumah Tinggal & Jumlah (unit) & Persentase (\%) \\
\hline Kayu berlantai tanah & 1 & 7,14 \\
\hline Kayu berlantai semen & 3 & 21,43 \\
\hline Semi permanen & 4 & 28,57 \\
\hline Permanen & 6 & 42,86 \\
\hline Jumlah & 14 & 100,00 \\
\hline
\end{tabular}

\section{Sumber: Data Primer 2019}

Pembangunan jembatan pada saat pemasangan tiang dengan melakukan pemboman menyebabkan getaran dan berdampak terhadap kondisi konstruksi bangunan rumah tinggal masyarakat pesisir di Kelurahaan Poasia Kecamatan Abeli Kota Kendari yang berada di kawasan pembangunan jembatan bahteramas menjadi memiliki umur bangunan berkurang dari umur seharusnya.

\subsection{Pembahasan}

Pada perekonomian modern, setiap kegiatan mempunyai keterkaitan dengan kegiatan lainnya. Demikian halnya juga dengan pembangunan inftrastruktur, memberikan dampak terhadap kegiatan masyarakat. Dampak tersebut dapat mencakup dapak sosial maupun ekonomi. Hasil penelitian pembangunan jembatan Bahteramas terhadap kondisi sosial ekonomi masyarakat menunjukkan bahwa 
pembangunan jembatan tidak berdampak signifikan pada variabel jenis pekerjaan masyarakat sekitar pembangunan jembatan. Hal ini disebabkan karena masyakarakat sekitar pembangunan jembatan tidak dilibatkan sebagai pekerja dalam proses pembangunan jembatan Bahteramas. Masyarakat masih tetap bekerja pada tiga jenis pekerjaan sebelum adanya pembangunan jembatan yaitu nelayan, pedagang dan lainnya. Perubahan hanya terjadi pada komposisi jumlah, dimana terjadi peningkatan jumlah pada jenis pekerjaan pedagang. Hasil penelitian ini sejalan dengan penelitian yang dilakukan oleh Muhsin (2012), dan Ruslan (2018) bahwa pembangunan infrastruktur memiliki dampak peningkatan kesempatan kerja. Meskipun hasil penelitian menunjukkan tidak ada penyerapan tenaga kerja pada proses pembangunan jembatan, namun membangunan jembatan memberi dampak tidak langsung yaitu masyarakat bekerja sebagai pedagang, hal ini terjadi karena masyarakat melihat peluang dari kebutuhan para pekerja pembangunan jembatan.

Untuk variabel tingkat pendapatan masyarakat pesisir di Kelurahan Poasia yang berada di kawasan pembangunan jembatan Bahteramas, adanya pembangunan jembatan Bahteramas terjadinya peningkatan pendapatan yaitu pada masyarakat yang bekerja sebagai pedagang, hal ini diakibatkan oleh kegiatan konsumsi yang dilakukan oleh para pekerja jembatan yang membeli kebutuhan sehari-hari mereka pada pedagang sekitar pembangunan jembatan. Hasil penelitian ini sejalan dengan hasil penelitian Sudarsana (2011), lek (2013 dan Ruslan (2018) bahwa pembangunan infrastruktur memberi dampak positif terhadap ekonomi masyarakat yaitu mengalami peningkatan pendapatan.

Dampak kesehatan yang dialami oleh masyarakat sekitar pembangunan jembatan Bahteramas adalah gangguan pernapasan dan kebisingan sebagai akibat dari debu dan peledakan bom dalam pembangunan jembatan. Hasil penelitian ini sejalan dengan hasil penelitian yang dilakukan oleh Prawiro (2014) yang melakukan penelitian dampak pembangunan jalan laying. Hasil penelitiannya, bahwa mayoritas responden di sepanjang jalan mengalami gangguan berupa kebisingan, polusi udara, kemacetan lalu lintas. Dan penelitian yang dilakukan oleh Ruslan dan Tamzil (2018) bahwa pembangunan infrastruktur jembatan Bahteramas menimbulkan polusi udara. Mahagana dan Cahya (2013) merinci dampak negatif sosial ekonomi pembangunan infrastruktur, meliputi keresahan masyarakat, penurunan kualitas udara, dan terganggunya aliran permukaan.

Pembangunan jembatan pada saat pemasangan tiang dengan melakukan pemboman menyebabkan getaran dan berdampak terhadap kondisi konstruksi bangunan rumah tinggal masyarakat pesisir di Kelurahaan Poasia Kecamatan Abeli Kota Kendari yang berada di kawasan pembangunan jembatan bahteramas menjadi memiliki umur bangunan berkurang dari umur seharusnya.

\section{Kesimpulan}

Berdasarkan hasil dan pembahasan dapat kesimpulan bahwa: (1) Pembangunan jembatan tidak berdampak signifikan pada jenis pekerjaan masyarakat sekitar pembangunan jembatan. Hal ini disebabkan karena tidak ada keterlibatan masyarakat sebagai pekerja dalam proses pembangunan jembatan Bahteramas. Masyarakat masih tetap bekerja pada tiga jenis pekerjaan sebelum 
adanya pembangunan jembatan yaitu nelayan, pedagang dan lainnya. Perubahan hanya terjadi pada komposisi jumlah, dimana terjadi peningkatan jumlah pada jenis pekerjaan pedagang; (2) Pembangunan jembatan Bahteramas terjadinya peningkatan pendapatan yaitu pada pedagang, hal ini diakibatkan oleh kegiatan konsumsi yang dilakukan oleh para pekerja jembatan yang membeli kebutuhan sehari-hari pada pedagang sekitar pembangunan jembatan; (3) Dampak kesehatan yang dialami oleh masyarakat sekitar pembangunan jembatan Bahteramas adalah gangguan pernapasan dan kebisingan sebagai akibat dari debu dan peledakan bom dalam pembangunan jembatan; (4) Pembangunan jembatan pada saat pemasangan tiang dengan melakukan pemboman menyebabkan getaran dan berdampak terhadap kondisi konstruksi bangunan rumah tinggal masyarakat pesisir di Kelurahaan Poasia Kecamatan Abeli Kota Kendari yang berada di kawasan pembangunan jembatan bahteramas menjadi memiliki umur bangunan berkurang dari umur seharusnya.

\section{Daftar Pustaka}

Arikunto, S. (2006). Prosedur Penelitian Suatu Pendekatan Praktek. Jakarta: Rineka Cipta.

lek, M. (2013). Analisis Dampak Pembangunan Jalan terhadap Pertumbuhan Usaha Ekonomi Rakyat di Pedalaman May Barat Provinsi Papua Barat: Studi Kasus di Distrik Ayamaro, Aitinyo, dan Aifat. . Jurnal Ekonomi Kuantitatif Terapan.

Made Avadhuta Austinov Mahagana, C. B. (2013). Study Kelayakan Jalan Akses Jembatan Baru Ploso Di Kabupaten Jombang-Jawa Timur. Jurnal TeknisITS, E-75-E77.

Muhsin, T. (2012). Kebutuhan Pembangunan Infrastruktur Dalam Pengembangan Wilayah (Studi Kasus Pembangunan Jembatan Bahteramas Kota Kendari). ITS.

Pamungkas, B. T. (2009). Pengaruh Infrastruktur Ekonomi, Sosial dan Adminitrasi/Institusi Terhadap Pertumbuhan Propinsi-Propinsi Di Indonesia. lib.ui.ac.id.

Prawiro, V. S. (2014). Kemungkinan Perubahan Guna Lahan Akibat Pembangunan Jalan Layang Non-Tol Antasari Blok M Berdasarkan Persepso Masyarakat. Perencanaan Wilayah dan Kota A SAPPK 1 (2).

Ruslan, P. T. (2018). Pengaruh Jembatan Bahteramas dan Dampak Bagi Masyarakat (Studi Kasus Di Kelurahan Kandai Kecamatan Kendari Kota Kendari. Neo-Societas Vol 3 No 2, 381-388.

Sudarsana, D. K. (Juli 2011). 2011. Penyertaan Ekonomi Makro Berupa PDRB dalam Ekonomi Pembangunan Jalan Penghubung Bali Utara - Selatan. . Jurnal Ilmiah 15 (2). 